\title{
Absence of Long-Term Depression in the Visual Cortex of Glutamic Acid Decarboxylase-65 Knock-Out Mice
}

\author{
Se-Young Choi, ${ }^{*}$ Bernardo Morales, ${ }^{1 *}$ Hey-Kyoung Lee, ${ }^{2}$ and Alfredo Kirkwood ${ }^{1}$ \\ ${ }^{1}$ Department of Neuroscience and 2 Howard Hughes Medical Institute, Mind Brain Institute, Johns Hopkins University, \\ Baltimore, Maryland 21218
}

\begin{abstract}
Long-term depression (LTD) is widely considered a mechanism for experience-induced synaptic weakening in the brain. Recent in vivo studies on glutamic acid decarboxylase [GAD 65 $(-/-)]$ knock-out mice indicates that GABAergic synaptic inhibition is also required for the normal weakening of deprived inputs in the visual cortex. To better understand how GABAergic inhibition might control plasticity, we assessed the status of synaptic inhibition and LTD in visual cortical slices of GAD 65 knock-out mice. We found the following: (1) the efficacy of GABAergic synapses during repetitive activation is reduced in
\end{abstract}

GAD 65 (-/-) mice; (2) the induction of LTD is impaired in the visual cortex of GAD 65 (-/-) mice; and (3) chronic, but not acute, treatment with the benzodiazepine agonist diazepam restores LTD in GAD $65(-/-)$ mice. These results suggest that a certain inhibitory tone is required for the induction of LTD in visual cortex. We propose that the lack of visual cortical LTD in GAD 65 (-/-) may account for the lack of experiencedependent plasticity in these mice.

Key words: critical period; synaptic plasticity; GABA; neocortex; IPSC; synaptic inhibition
Shortly after birth, the visual cortex enters into a brief critical period of enhanced plasticity (Hubel and Wiesel, 1970). At this stage, a simple alteration of visual experience, such as monocular deprivation, selectively weakens the deprived inputs, shifting the eye preference of cortical cells toward the nondeprived eye (Fagiolini et al., 1994; Gordon et al., 1996). It is widely believed that NMDA receptor-dependent forms of synaptic modification, such as long-term potentiation (LTP) and longterm depression (LTD), are essential for developmental plasticity in the visual and other sensory cortices (Singer, 1995; Daw et al., 1999; Rittenhouse et al., 1999; Di Cristo et al., 2001). In the context of this idea, it has been proposed that the critical period results from the delayed maturation of the GABAergic system (Komatsu, 1983; Kirkwood and Bear, 1994). The recruitment of GABAergic synaptic inhibition restricts the induction of synaptic plasticity (Kirkwood and Bear, 1994); hence, its late maturation (Blue and Parnavelas, 1983; Luhmann and Prince, 1991; Guo et al., 1997) would provide a window of opportunity for plasticity to occur (Huang et al., 1999; Rozas et al., 2001).

Recently, however, this view has been challenged based on results obtained with knock-out $(\mathrm{KO})$ mice that lack glutamic acid decarboxylase 65 (GAD 65), one of the two isoforms of the GABA synthesizing enzyme GAD 65. In GAD $65(-/-)$ mice, monocular deprivation does not cause the normal shift in ocular dominance unless synaptic inhibition is pharmacologically enhanced by local application of diazepam (Hensch et al., 1998).

\footnotetext{
Received Dec. 18, 2001; revised March 15, 2002; accepted April 4, 2002.

This study was supported by National Institutes of Health Grants R01EY12124-03 and P50-MH58880-01. We thank Dr. Mark Bear for valuable comments on this manuscript and Dr. Jokubas Zirbukus for technical help.

*S.-Y.C. and B.M. contributed equally to this work.

Correspondence should be addressed to Alfredo Kirkwood, Mind Brain Institute, Johns Hopkins University, 338 Krieger Hall, 3400 North Charles Street, Baltimore, MD 21218. E-mail: kirkwood@jhu.edu.

Copyright (C) 2002 Society for Neuroscience $\quad 0270-6474 / 02 / 225271-06 \$ 15.00 / 0$
}

Although these results stress the importance of GABAergic inhibition in visual plasticity, the cellular basis for the lack of plasticity in GAD $65(-/-)$ mice remains unknown. The induction of LTP and LTD in visual cortical slices from GAD $65(-/-)$ mice was reportedly normal, supporting arguments against the involvement of these mechanisms of synaptic modification in visual cortical plasticity. In view of the important implications of such a conclusion, we set out to reexamine in GAD $65(-/-)$ mice the status of LTD, perhaps the most relevant mechanism of plasticity to account for the effects of monocular deprivation. Here we report that the induction of LTD is impaired in young GAD $65(-/-)$ mice, yet LTD can be restored in these mice by chronic application of diazepam. Our reexamination of the status of NMDA-dependent plasticity forces a fundamental revision in how in vivo experiments on GAD $65(-/-)$ are interpreted.

\section{MATERIALS AND METHODS}

Coronal slices $(300-400 \mu \mathrm{m})$ from the visual cortex and hippocampus of GAD $65(-/-)$ mice (Kash et al., 1997) were prepared as described previously (Kirkwood and Bear, 1994). Briefly, after sectioning in icecold oxygenated $\left(95 \% \quad \mathrm{O} 2-5 \% \mathrm{CO}_{2}\right)$ dissection buffer (in mM: 212.7 sucrose, $5 \mathrm{KCl}, 1.25 \mathrm{NaH}_{2} \mathrm{PO}_{4}, 3 \mathrm{MgCl}_{2}, 1 \mathrm{CaCl}_{2}, 26 \mathrm{NaHCO}_{3}, 10$ dextrose, and 10 kynurenate), slices were transferred to a storage chamber containing normal artificial CSF (ACSF) for at least $1 \mathrm{hr}$ before recording. Normal ACSF is similar to the dissection ACSF except that sucrose is replaced by $124 \mathrm{~mm} \mathrm{NaCl}, \mathrm{MgCl}_{2}$ is lowered to $1 \mathrm{~mm}, \mathrm{CaCl}_{2}$ is raised to $2 \mathrm{~mm}$, and kynurenate is omitted.

For whole-cell voltage clamp, the cells were visually identified with an infrared differential interference contrast Zeiss (Oberkochen, Germany) microscope. Patch pipettes $(2-4 \mathrm{M} \Omega$ ) were filled with internal solution consisting of (in mM): 130 Cs-gluconate, $8 \mathrm{KCl}, 10$ EGTA, 10 HEPES, and 1 QX-314, pH 7.4 (275-285 mOsm). In the experiments described in Figure 2, $40 \mathrm{~mm}$ Cs-gluconate was replaced by $40 \mathrm{~mm} \mathrm{CsCl}$. The reversal potential of the GABAergic currents was close to the value predicted by the Nernst potential of $\mathrm{Cl}^{-}(-64.6 \pm 2.0 \mathrm{mV}, n=5$ and $-30.5 \pm 1.3 \mathrm{mV}$, $n=4$ for the first and second solutions, respectively). The junction potential (typically $<5 \mathrm{mV}$ ) was compensated. Only cells with membrane 
potentials more negative than $-65 \mathrm{mV}$, access resistance smaller than 20 $\mathrm{M} \Omega(8-18 \mathrm{M} \Omega$, compensated at $80 \%)$, and input resistance larger than $100 \mathrm{M} \Omega(130-410 \mathrm{M} \Omega)$ were studied.

Synaptic responses were evoked with 15-300 $\mu \mathrm{A}, 0.2 \mathrm{msec}$ current pulses delivered with a bipolar stimulating electrode (200 $\mu \mathrm{m}$ diameter; Frederick Haer Co., Bowdoinham, ME). Microelectrodes were filled with ACSF (1-2 M $\mathrm{A}$ ) for extracellular recordings. In visual cortical experiments, the stimulating electrodes were placed in the middle of the cortical thickness, approximately equidistant from the pia and the white matter, and the responses were recorded in layers II/III. In hippocampal experiments, the stimulating and the recording electrodes were places in the dendritic field of the CA1 region. Synaptic responses were quantified as the initial slope of the field potential (FP) in CA1 and the amplitude of the maximum negative FP in layer III. Changes in the amplitude of the maximum negative FP reflect changes in the magnitude of a synaptic current sink (Aizenman et al., 1996) and correlate with changes in the initial slope of EPSPs recorded intracellularly in layer III neurons (Kirkwood and Bear, 1994). Long-term depression was induced by delivering 900 pulses at $1 \mathrm{~Hz}$. Only data from slices with stable recordings $(<5 \%$ change over the baseline period) were included in the analysis. All data are presented as average \pm SEM normalized to the preconditioning baseline. Statistical significance was assessed using $t$ test or two-way repeated-measures ANOVA, followed by the Fisher's post hoc test. Diazepam was dissolved in $0.01 \%$ DMSO. All drugs were purchased from Sigma/RBI (Poole, UK).

\section{RESULTS}

All experiments were performed in visual cortical slices prepared from 3-week-old [postnatal day 21 (P21) to P27] GAD 65(-/-) mice and age-matched wild-type littermates. Stimulation was applied to layer IV, and synaptic responses were recorded in layer II/III.

\section{Normal inhibitory input in GAD $65(-/-)$ mice}

Indirect evidence from field recordings and high-K-induced GABA release suggested a deficit in GABAergic transmission in the visual cortex of GAD $65(-/-)$ (Hensch et al., 1998). To assess the status of GABAergic transmission more directly, we studied evoked IPSCs under whole-cell voltage-clamp conditions. Monosynaptic IPSCs were recorded at $0 \mathrm{mV}$ and in the presence of $10 \mu \mathrm{M}$ CNQX and $100 \mu \mathrm{M}$ APV to block fast glutamatergic transmission. We first measured the magnitude of the maximal IPSC, which provides a mean of comparing the total GABAergic inputs converging into pyramidal cells (Ling and Benardo, 1999). Previously, we reported that BDNFoverexpressing mice, which exhibit an early developmental increase in GAD 65 puncta, also show an accelerated developmental increase in the maximal IPSC (Huang et al., 1999). Thus, we expected a reduced maximal IPSC in the GAD 65 $(-/-)$ mice. Figure 1 summarizes the results. To our surprise, but in line with a previous study in CA1 (Tian et al., 1999), we found no significant difference $(p=0.28)$ in the magnitude of the maximal IPSCs between GAD $65(-/-)(529 \pm 33 \mathrm{pA}$; $n=11)$ and their age-matched wild-type littermates (561 \pm 25 $\mathrm{pA} ; n=11)$. These results suggest that total GABAergic input converging onto pyramidal cells is not affected by the deletion of the GAD 65 gene.

\section{Reduced efficacy of GABAergic synaptic transmission during repetitive activation in GAD 65}

In cortex, inhibitory synaptic transmission is greatly attenuated during repetitive activation, likely attributable to the progressive depletion of the releasable pool of vesicles (Galarreta and Hestrin, 1998; Varela et al., 1999). GAD 65, which is specifically localized in the axon terminals, is likely an important factor
A
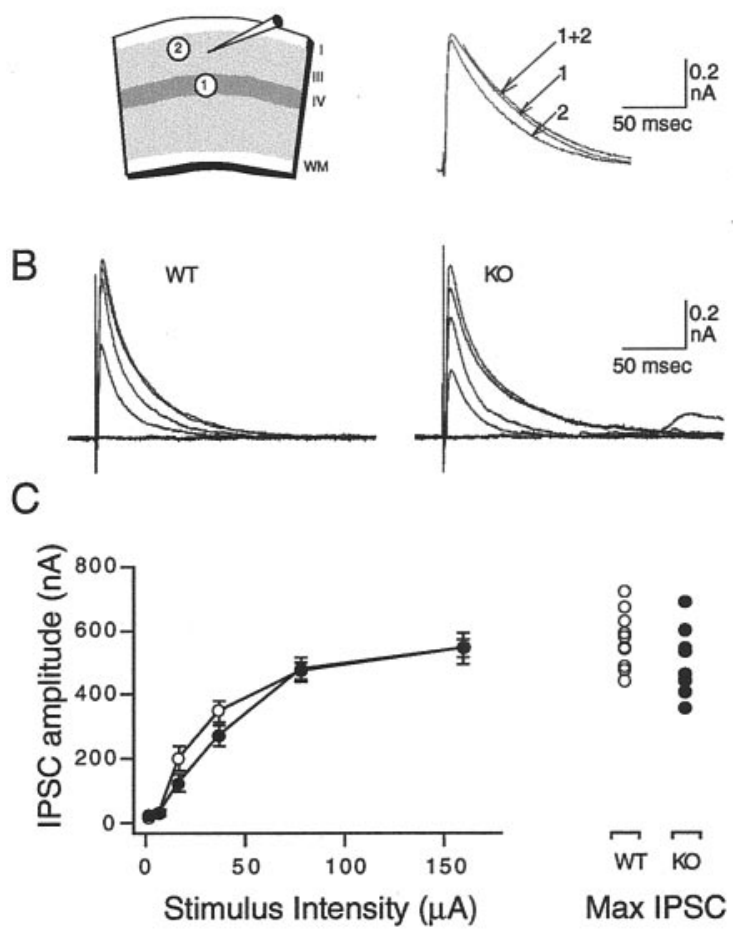

Figure 1. Normal number of inhibitory inputs in GAD $65 \mathrm{KO}$ mice. $A$, Stimulation in layer IV effectively recruits the maximal IPSCs in layer II/III cells. Diagram on the left depicts stimulation-recording configuration. Traces are examples of maximal responses evoked by layer IV stimulation (1), lateral stimulation (2), and layer IV and lateral stimulation together $(1+2) . B, C$, Similar relationship between stimulus intensity and IPSC magnitude in GAD $65 \mathrm{KO}$ mice and their wild-type (WT) littermates. $A$, Example IPSCs evoked by a series of stimulus of increasing intensity $(5,10,20,40,80$, and $160 \mathrm{~mA})$ recorded in layer II/III pyramidal cells from wild type (left) and an age-matched GAD $65 \mathrm{KO}$ littermate (right). B, Relationship between IPSC magnitude and stimulus intensity for wild type (open circles; 11 cells, 6 mice) and GAD $65 \mathrm{KO}$ littermates ( filled circles; 11 cells, 6 mice). Indicated on the right are the maximal IPSC amplitudes (obtained at $160 \mathrm{~mA}$ ) for all individual experiments.

determining the size of the releasable pool and/or its replenishment after depletion (Tian et al., 1999). In fact, GABAergic transmission during tetanic stimulation is impaired in the CA1 region of the hippocampus of GAD 65 KOs (Tian et al., 1999). The results shown in Figure $2 A$ confirmed that this is also the case in visual cortex. In these experiments, the stimulation intensity was adjusted to evoke IPSCs of similar amplitude in cells from GAD $65 \mathrm{KO}(198 \pm 5 \mathrm{pA} ; n=8)$ and wild-type $(202 \pm 8 ; n=11)$ mice. However, the response to a $1 \mathrm{sec} 100$ $\mathrm{Hz}$ stimulus train was much reduced in the GAD $65 \mathrm{KO}$ cells (total charge, $358 \pm 25 \mathrm{pC}$ in GAD $65 ; 493 \pm 58 \mathrm{pC}$ in wild type; $p=0.001)$. Indirect evidence from field potential recordings suggest that, in cortex, GABAergic transmission might be impaired at even lower frequencies (Hensch et al., 1998). Therefore, we studied the response of layer II/III cells to trains of 15 stimulation pulses delivered at different frequencies $(50,30$, and $1 \mathrm{~Hz})$. Because prolonged depolarization can affect the evoked IPSC (Alger and Pitler, 1995), these experiments were performed at $-70 \mathrm{mV}$ rather than at $0 \mathrm{mV}$. To allow the measurement of IPSCs at $-70 \mathrm{mV}$, the reversal 
A
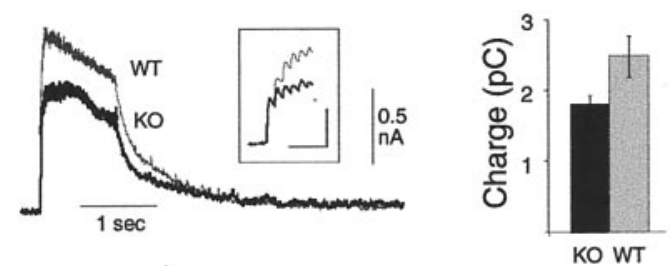

B
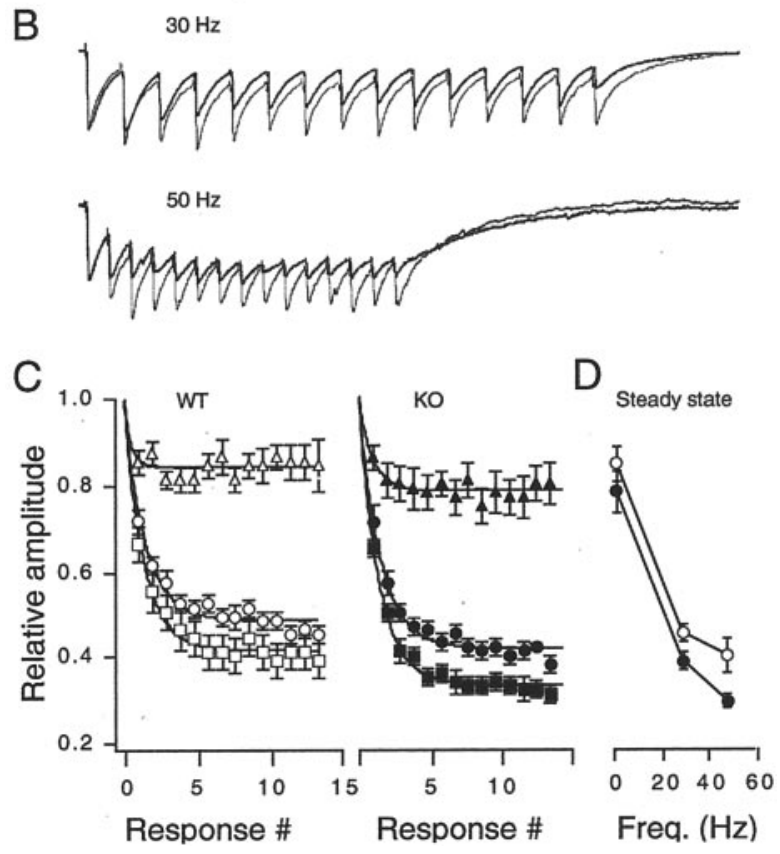

Figure 2. Reduced efficacy of GABAergic synaptic transmission during repetitive activation in GAD $65 \mathrm{KO}$ mice. $A$, Reduced response to tetanic stimulation (100 pulses at $1 \mathrm{~Hz}$ ) in cells from GAD $65 \mathrm{KO}$ mice. Superimposed traces represent the average of the responses of eight cells from GAD $65 \mathrm{KO}$ mice (thick trace) and 11 cells from agematched wild-type (WT) littermate (thin trace) mice. Stimulation intensity was adjusted to evoke single IPSCs of similar amplitude in both genotypes. The inset shows the same average responses at higher temporal resolution. The total charge flow during the tetanus is shown on the right bar graph. The response of cell was integrated and then averaged across genotypes. $B$, Examples of responses evoked by 15 pulse trains delivered at $30 \mathrm{~Hz}$ (top) and $50 \mathrm{~Hz}$ (bottom) in cells from a GAD $65 \mathrm{KO}$ (thick trace) mouse and its age-matched wild-type littermate (thin trace). The traces (averages of 4 responses) have been normalized to the response to the first pulse of the train. $C$, Average attenuation of the IPSC amplitude during 15 pulse trains delivered at $1 \mathrm{~Hz}$ (triangles), $30 \mathrm{~Hz}$ (circles), and $50 \mathrm{~Hz}$ (squares). Results from wild type are shown on the left, and results from GAD $65 \mathrm{KOs}$ are on the right. The curves are single exponentials that give the best fit to the data. $D$, Relative amplitudes of IPSC at steady state (average of the last 3 responses of a train) across different stimulation frequencies. Open symbols, Wild type; filled symbols, GAD $65 \mathrm{KO}$.

potential of $\mathrm{Cl}^{-}$was shifted to a more positive value by increasing the $\left[\mathrm{Cl}^{-}\right]$in the recording pipette (see Materials and Methods). As shown in Figure $2 B-D$, during the train stimulation, the response magnitude rapidly decreased until it reached a steady level that depended on the stimulation frequency. The degree of depression at the steady state was consistently larger in the GAD $65(-/-)$ at all the frequencies tested. A statistical analysis revealed that the differences in frequency-dependent depression between GAD $65(-/-)$ and wild types were highly significant (two-factor ANOVA; $F_{(1,59)}$
$=15.66 ; p=0.0002)$. These results indicate that the ablation of GAD 65 reduces the efficacy of inhibitory transmission during prolonged activation.

\section{Impaired LTD in visual cortex of GAD 65(-/-) mice}

Experimental evidence indicates that LTD-like mechanisms are involved in the ocular dominance shifts caused by monocular deprivation in kittens (Rittenhouse et al., 1999). Thus, assessing the status of LTD in the GAD $65 \mathrm{KO}$ is of obvious relevance for understanding results obtained with monocular deprivation in these mice. To investigate how the ablation of GAD 65 affects LTD, we used the standard protocol of prolonged low-frequency stimulation (LFS) (900 pulses at $1 \mathrm{~Hz}$ ), which induces robust LTD in young animals in a number of regions, including the cortex. For comparative purposes, we also studied LTD in the Schaffer collateral $\rightarrow$ CA1 pathway in the hippocampus. All experiments were done "blind" to the genotype, and Figure $3 \mathrm{~A}$ summarizes the results. In the visual cortex, LFS reliably induced LTD in slices from the wild-type mice $(80.1 \pm 4.3 \%$; $n=4$ mice; 13 slices), but it barely affected the responses recorded in the $\mathrm{KO}$ littermates (97.4 $\pm 2.7 ; n=4$ mice; 15 slices). This difference was highly significant $(p<0.001)$. In contrast, in CA1, LFS induced comparable levels of LTD $(p=0.90)$ in slices from wild-type mice $(77.6 \pm 6.1 ; n=4$ and 9$)$ and their KO littermates $(78.5 \pm$ $3.1 ; n=8$ and 18). Together, these results indicate that the ablation of GAD 65 impairs the induction of LTD specifically in the visual cortex.

\section{Chronic but not acute application of diazepam restores cortical LTD in GAD 65 KO mice}

The effects of monocular deprivation can be restored in GAD $65(-/-)$ mice by infusing the benzodiazepine agonist diazepam into the cortex (Hensch et al., 1998). We asked whether this effect of diazepam was the result of a rescued LTD. It is well established that GABAergic inhibition regulates the induction of synaptic plasticity by limiting the activation of NMDA receptors (Artola et al., 1990; Kirkwood and Bear, 1994). Indeed, manipulations that reduce inhibition also decrease the magnitude of LTD, whereas manipulations that enhance inhibition also increase LTD (Steele and Mauk, 1999). Therefore, we tested whether potentiating the inhibitory response with benzodiazepines restores LTD in the visual cortex of GAD $65(-/-)$. In a first series of experiments, diazepam was acutely applied to the bath. At this concentration $(15 \mu \mathrm{M})$, diazepam reliably enhanced the amplitude $(170 \%$ of control; $p=0.048$ ) and duration (135\% of control; $p=$ $0.027)$ of the IPSC recorded in cells from GAD $65(-/-)$ mice ( $n=5$; data not shown) (Segal and Barker, 1984; Hensch et al., 1998; Rozas et al., 2001). However, as shown in Figure 4, such bath applications of diazepam failed to restore LTD in GAD $65(-/-)$, and there was no difference $(p=0.89)$ in the magnitude of LTD obtained in the presence $(96.2 \pm 3.0 ; n=$ $5 ; 15$ ) of the drug or in interleaved controls (only DMSO, $95.4 \pm 3.7 ; n=5 ; 9)$. Because experience-dependent visual cortex plasticity was rescued in GAD $65(-/-)$ animals chronically treated with diazepam (Hensch et al., 1998), we asked whether a prolonged exposure to diazepam is necessary to restore LTD. In these experiments, all pups in a given litter were treated with diazepam (10 mg/kg, i.p., daily) for $6 \mathrm{~d}$ before the experiments. This dosage of diazepam has been 
Figure 3. Induction of LTD with $1 \mathrm{~Hz}$ LFS is impaired in the visual cortex but not in the CA1 region of GAD 65 KO mice. The graphs depict average changes in the evoked field potentials induced by LFS $(1 \mathrm{~Hz}, 15 \mathrm{~min})$ in slices of visual cortex $(A)$ and CA1 $(B)$ prepared from 3-week-old wild-type ( $W T$ ) mice (open circles) and their GAD 65 KO littermates ( filled circles). The LTD magnitude for each individual experiment (measured $1 \mathrm{hr}$ after LFS) is shown at the right of each graph. Example field potential traces from experiments performed in wild-type (top) and KO (bottom) mice are shown in the right. The superimposed traces are averages of four consecutive responses recorded $1 \mathrm{~min}$ before (thin traces) and $1 \mathrm{hr}$ after (thick traces) LFS.
A
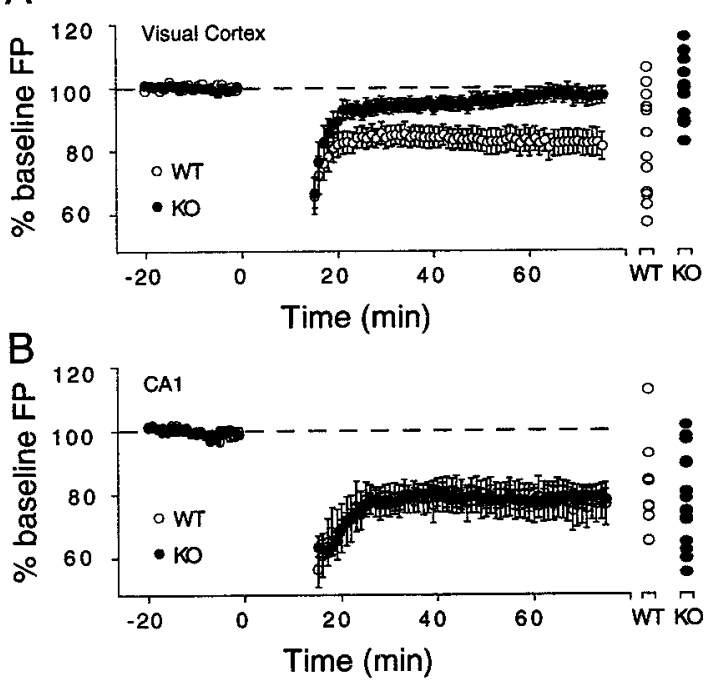

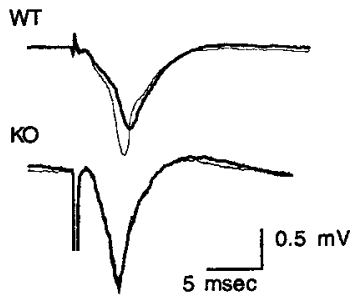

WT

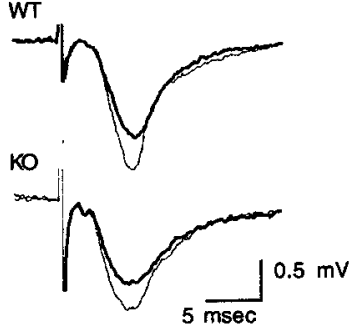

A
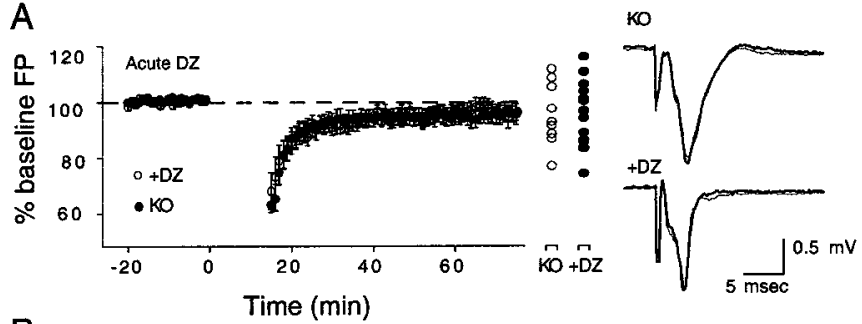

B
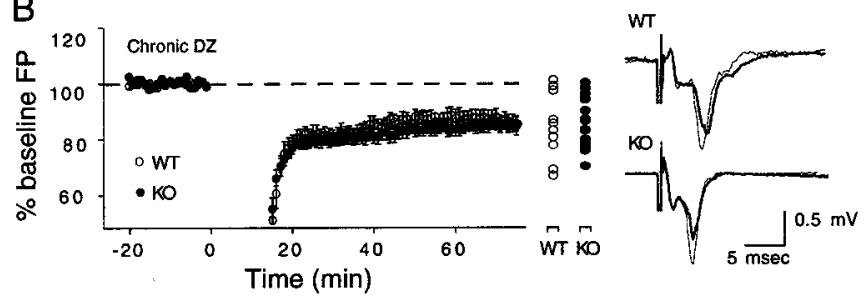

Figure 4. Chronic but not acute application of diazepam $(D Z)$ restores LTD in the visual cortex of GAD $65 \mathrm{KO}$ mice. $A$, LFS does not induce LTD in slices from GAD $65 \mathrm{KO}$ in control conditions (DMSO; open circles) or when $15 \mu \mathrm{M}$ diazepam was continuously bath applied from 20 min before experiment ( filled circles). B, Pretreatment with diazepam (10 $\mathrm{mg} / \mathrm{kg}$ daily; 5-6 d) abolishes the differences in LTD between wild-type (open circles) and GAD $65 \mathrm{KO}$ (filled circles) mice. As in Figure 3, the results from all individual experiments are depicted on the right of each graph. Representative field potential traces for each experimental condition are shown on the far right. The superimposed traces are averages of four consecutive responses recorded $1 \mathrm{~min}$ before (thin traces) and $1 \mathrm{hr}$ after (thick traces) LFS.

shown previously to reduce excitability and to affect plasticity (Levkovitz et al., 1999). At the end of the treatment, the heterozygotes were discarded, and LTD was measured in the GAD $65(-/-)$ and wild-type mice. The experimenter was blind to the genotype of the animal. As illustrated in Figure $4 B$, in slices prepared from diazepam-treated animals, LFS resulted in robust and comparable $(p=0.91)$ LTD in both wild type $(84.9 \pm 3.4 ; n=4$ and 11$)$ and GAD $65(-/-)(85.4 \pm 2.2$ $n=5$ and 15). In both cases, the magnitude of LTD was comparable with the one obtained in slices prepared from untreated wild-type animals $(\sim 80 \%)$ (Fig. 1). These results

indicate that chronic but not acute exposure to diazepam is sufficient to restore LTD in GAD $65(-/-)$ mice.

\section{DISCUSSION}

Previous studies on GAD $65(-/-)$ mice reported a marked increase in cortical excitability and a severe reduction in experience-evoked visual cortical plasticity (Kash et al., 1997; Hensch et al., 1998). Both outcomes were attributed to the reduced GABAergic function associated with the elimination of GAD 65 . We found that, in addition, at least one mechanism of synaptic modification, LTD, is impaired in the visual cortex of GAD 65 $(-/-)$ mice. As discussed below, such findings bear obvious relevance for understanding the lack of visual cortical plasticity in GAD $65(-/-)$.

GAD 65, one of the two isoforms of the GABA-synthesizing enzyme GAD, locates primarily in the axon terminals (Esclapez et al., 1994). Because of its subcellular location and dependence of cofactors, GAD 65 is believed to be important at times of increased synaptic activity. In CA1, the genetic deletion of GAD 65 does not affect basal GABAergic transmission, but it compromises the ability to sustain repetitive activation. Similarly, in visual cortex, the steady-state response to prolonged stimulation was clearly reduced in GAD $65(-/-)$. In contrast, the magnitude of the maximal IPSC, which reflects the number and potency of GABAergic inputs targeting a cell (Ling and Benardo, 1999), was not affected by the mutation. Thus, the availability of GAD 65 appears to be a limiting factor for the efficacy of transmission at high frequencies but not the potency or number of GABAergic inputs in visual cortex.

Besides the expected deficit in inhibitory transmission, the ablation of GAD $65(-/-)$ also impaired LTD of excitatory transmission in visual cortex. In a previous study, Hensch et al. (1998) reported normal LTD and LTP in the GAD $65(-/-)$ mice. This discrepancy might be related to the age of the animals used. In mice, unlike most other species studied, the induction of LTD with $1 \mathrm{~Hz}$ LFS is strongly regulated during development such that, after P30, $1 \mathrm{~Hz}$ no longer induces much LTD, not even in CA1 (Mayford et al., 1995; Kirkwood et al., 1997) (our unpublished observations). In the study of Hensch et al. (1998), the animals were older (P24-P33) and showed much less LTD (10\% LTD in wild types) 
compared with our study (P21-P27; 20\% LTD in wild types). The smaller magnitude of depression combined with short preconditioning baselines (only $10 \mathrm{~min}$ by Hensch et al., 1998) makes it difficult to discern whether those changes represent LTD or a drift in basal responses. In any case, the smaller magnitude of LTD in wild types would make those measurements unsuitable for detecting a deficit in LTD.

We showed that LTD could be rescued in GAD $65(-/-)$ mice by chronically treating the animals with diazepam. However, acute application of diazepam did not restore LTD. These results suggest that the LTD deficit is not directly attributable to reduced inhibitory tone per se during $1 \mathrm{~Hz}$ conditioning stimulation. An alternative hypothesis is that the LTD deficit in GAD $65(-/-)$ mice is a consequence of the history of enhanced cortical activity in vivo. It is also possible that LTD is intact in GAD $65(-/-)$ mice, but the mutation affected cortical circuits in such a way that they are not effectively recruited by $1 \mathrm{~Hz}$ conditioning. Whether the increased activity in GAD $65(-/-)$ mice already induced LTD and saturated it, or whether it caused the downregulation of the LTD mechanisms or affected the frequencydependency of its induction, remains to be investigated. In this respect, it is worth mentioning that, in dark-reared animals, in which increased spontaneous activity and cortical excitability suggest a weaker inhibition (Benevento et al., 1992), the induction of LTD ex vivo is clearly downregulated (Kirkwood et al., 1996). In any case, these results suggest that the inhibitory tone plays an important role in the regulation of synaptic plasticity in visual cortex.

In contrast to visual cortex, the induction of LTD was normal in the CA1 region of GAD $65(-/-)$. It is possible that the alterations in GABAergic function in GAD $65(-/-)$ are more severe in cortex than in hippocampus. Consistent with that idea, the deficit in GABAergic transmission were revealed by a much milder type of stimulation in cortex (15 pulses at $30 \mathrm{~Hz}$ ) than in CA1 (100 pulses at $100 \mathrm{~Hz}$ by Tian et al., 1999). Alternatively, LTD in cortex might be more responsive to changes in GABAergic transmission. A clear example of higher vulnerability of cortical plasticity is provided by the $\alpha$-CaM kinase II knock-out heterozygotes, which display selective deficit of LTP in the cortex but not in CA1(Frankland et al., 2001). The seemingly labile synaptic plasticity in the cortex might be related to the fact that its induction is tightly regulated (Kirkwood et al., 1999; Kojic et al., 2000).

In the original characterization of visual cortical plasticity in GAD $65(-/-)$ mice, the lack of ocular dominance plasticity was attributed solely to the altered balance of excitation and inhibition. The possible role of NMDA receptor-dependent synaptic plasticity was dismissed on the grounds that LTP and LTD were normal in these mice (Hensch et al., 1998). Our results showing a profound deficit of LTD in younger animals are consistent with the alternative hypothesis that LTD is a mechanism for weakening inputs from the deprived eye (Rittenhouse et al., 1999). According to this view, the lack of LTD in GAD $65(-/-)$ would render these mice refractory to the normal effects of monocular deprivation. On the other hand, chronic diazepam would be expected to restore experience-dependent plasticity by rescuing LTD in these mice.

The importance of GABAergic circuits in visual cortical plasticity is well established, but their exact role has remained elusive and controversial at times, perhaps because most interpretations have focused on the direct inhibitory actions of GABAergic transmission. Our results indicate that the inhibitory tone might also regulate the modification of excitatory synapses, revealing an additional level of complexity in the interaction between excitatory and inhibitory circuits.

\section{REFERENCES}

Aizenman C, Kirkwood A, Bear M (1996) Current source density analysis of evoked responses in visual cortex in vitro: implications for the regulation of long-term potentiation. Cereb Cortex 6:751-758.

Alger BE, Pitler TA (1995) Retrograde signaling at GABAA-receptor synapses in the mammalian CNS. Trends Neurosci 18:333-340.

Artola A, Brocher S, Singer W (1990) Different voltage-dependent thresholds for inducing long-term depression and long-term potentiation in slices of rat visual cortex. Nature 347:69-72.

Benevento LA, Bakkum BW, Port JD, Cohen RS (1992) The effects of dark rearing on the electrophysiology of the rat visual cortex. Brain Res 572:198-207.

Blue ME, Parnavelas JG (1983) The formation and maturation of synapses in the visual cortex of the rat. II. Quantitative analysis. J Neurocytol 12:697-712.

Daw N, Gordon B, Fox K, Flavin H, Kirsch J, Beaver C, Ji Q, Reid S, Czepita D (1999) Injection of MK-801 affects ocular dominance shifts more than visual activity. J Neurophysiol 81:204-215.

Di Cristo G, Berardi N, Cancedda L, Pizzorusso T, Putignano E, Ratto GM, Maffei L (2001) Requirement of ERK activation for visual cortical plasticity. Science 292:2337-2340.

Esclapez M, Tillakaratne NJ, Kaufman DL, Tobin AJ, Houser CR (1994) Comparative localization of two forms of glutamic acid decarboxylase and their mRNAs in rat brain supports the concept of functional differences between the forms. J Neurosci 14:1834-1855.

Fagiolini M, Pizzorusso T, Berardi N, Domenici L, Maffei L (1994) Functional postnatal development of the rat primary visual cortex and the role of visual experience: dark rearing and monocular deprivation. Vision Res 34:709-720.

Frankland PW, O'Brien C, Ohno M, Kirkwood A, Silva AJ (2001) Alpha-CaMKII-dependent plasticity in the cortex is required for permanent memory. Nature 309:309-313.

Galarreta M, Hestrin S (1998) Frequency-dependent synaptic depression and the balance of excitation and inhibition in the neocortex. Nat Neurosci 1:539-541.

Gordon JA, Cioffi D, Silva AJ, Stryker MP (1996) Deficient plasticity in the primary visual cortex of $\alpha$-calcium/calmodulin-dependent protein kinase II mutant mice. Neuron 17:491-499.

Guo Y, Kaplan IV, Cooper NG, Mower G (1997) Expression of two forms of glutamic acid decarboxylase (GAD67 and GAD65) during postnatal development of the cat visual cortex. Brain Res Dev Brain Res 103:127-141.

Hensch TK, Faglioni M, Mataga N, Stryker MP, Baekkeskov S, Kash SF (1998) Local GABA circuit control of experience-dependent plasticity in developing visual cortex. Science 282:1504-1508.

Huang JZ, Kirkwood A, Pizzorusso T, Porciatti V, Morales B, Bear MF, Maffei L, Tonegawa S (1999) BDNF regulates the maturation of inhibition and the critical period of plasticity in mouse visual cortex. Cell 98:739-755.

Hubel DH, Wiesel TN (1970) The period of susceptibility to the physiological effects of unilateral eye closure in kittens. J Physiol (Lond) 206:419-436.

Kash SF, Johnson RS, Tecott LH, Noebels JL, Mayfield RD, Hanahan D, Baekkeskov S (1997) Epilepsy in mice deficient in the $65-\mathrm{kDa}$ isoform of glutamic acid decarboxylase. Proc Natl Acad Sci USA 94: 14060-14065.

Kirkwood A, Bear MF (1994) Hebbian synapses in visual cortex. J Neurosci 14:1634-1645.

Kirkwood A, Rioult MG, Bear MF (1996) Experience-dependent modification of synaptic plasticity in visual cortex. Nature 381:526-528.

Kirkwood A, Silva A, Bear MF (1997) Age-dependent decrease of synaptic plasticity in the neocortex of alphaCaMKII mutant mice. Proc Natl Acad Sci USA 94:3380-3383.

Kirkwood A, Rozas C, Kirkwood J, Perez F, Bear MF (1999) Modulation of long-term depression in visual cortex by acetylcholine and norepinephrine. J Neurosci 19:1599-1609.

Kojic L, Dyck RH, Gu Q, Douglas RM, Matsuraba J, Cynader MS (2000) Columnar distribution of serotonin-dependent plasticity within kitten striate cortex. Proc Natl Acad Sci USA 97:1841-1844.

Komatsu Y (1983) Development of cortical inhibition in kitten striate cortex investigated by a slice preparation. Dev Brain Res 8:

136-139.
Levkovitz Y, Avignone E, Groner Y, Segal M (1999) Upregulation of GABA neurotransmission suppresses hippocampal excitability and prevents long-term potentiation in transgenic superoxide dismutaseoverexpressing mice. J Neurosci 19:10977-10984.

Ling DS, Benardo L (1999) Restrictions on inhibitory circuits contribute 
to limited recruitment of fast inhibition in rat neocortical pyramidal cells. J Neurophysiol 82:1793-1807.

Luhmann HJ, Prince DA (1991) Postnatal maturation of the GABAergic system in rat neocortex. J Neurophysiol 65:247-263.

Mayford M, Wang J, Kandel E, O'Dell T (1995) CaMKII regulates the frequency-response function of hippocampal synapses for the production of both LTD and LTP. Cell 81:1-20.

Rittenhouse CD, Shouval HZ, Paradiso MA, Bear MF (1999) Monocular deprivation induces homosynaptic long-term depression in visual cortex. Nature 397:347-350.

(2001) Developmental inhibitory gate controls the relay of activity to the superficial layers of the visual cortex. J Neurosci 21:6791-6801.

Segal M, Barker JL (1984) Rat hippocampal neurons in culture: voltage- clamp analysis of inhibitory synaptic connections. J Neurophysiol 52: 469-487.

Singer W (1995) Development and plasticity of cortical processing architectures. Science 270:758-759.

Steele PM, Mauk MD (1999) Inhibitory control of LTP and LTD: stability of synapse strength. J Neurophysiol 81:1559-1566.

Tian N, Petersen C, Kash S, Baekkeskov S, Copenhagen D, Nicoll R (1999) The role of the synthetic enzyme GAD65 in the control of neuronal gamma-aminobutyric acid release. Proc Natl Acad Sci USA 96:12911-12916.

Varela JA, Song S, Turrigiano GG, Nelson SB (1999) Differential depression at excitatory and inhibitory synapses in visual cortex. J Neurosci 19:4293-4304. 